\title{
Ocular Findings in Neurofibromatosis Type1 and Literature Review
}

\author{
Chhaya Shinde ${ }^{1}$, Shruti Shirwadkar ${ }^{2 *}$, Ankita Patil ${ }^{3}$ and Fatima Siddiqui ${ }^{3}$ \\ ${ }^{1}$ Prof \& Head dept of Ophthalmology, Lokmanya Tilak Municipal Medical College \& General Hospital, India \\ ${ }_{2}^{2}$ Assistant professor, Lokmanya Tilak Municipal Medical College \& General Hospital, India \\ ${ }^{3}$ Resident doctor, Lokmanya Tilak Municipal Medical College \& General Hospital, India
}

Submission: December 18, 2017; Published: January 16, 2018

*Corresponding author: Shruti Shirwadkar, Assistant professor, Lokmanya Tilak Municipal medical college and General Hospital, Sion, Mumbai, India, Tel: +91-9892967320; Email: drshrutis@gmail.com

\footnotetext{
Abstract

To report cases of neurofibromatosis type 1 associated with ocular manifestation.
}

\section{Introduction}

Neurofbromatosis is a rare condition characterized by hamartomas of neural crest origin (phakomatosis). The condition is autosomal dominant, though spontaneous new mutations are not uncommon. The National Institutes of Health (NIH) divide neurofibromatosis into type 1 (NF1 or von Recklinghausen syndrome) and type 2 (NF2, acoustic neurofibromatosis, or central neurofibromatosis). Only $\sim 10 \%$ of $\mathrm{NF}$ patients have NF2, which is associated with bilateral acoustic neuromas/ schwannomas. The defect in NF2 is on chromosome 22q. In addition to acoustic neuromas, NF2 patients frequently have ependymomas of the spinal cord or multiple meningiomas.

$85 \%$ of patients with neurofibromatosis suffer from NF1, similar to the patient in these case reports. The genetic defect in NF1 is almost always a mutation in the neurofibromin gene on chromosome 17 (17q11.2). Neurofibromin normally functions to down-regulate the p21 ras on co-protein. Loss of the tumor suppressor function of neurofibromin leads to proliferation of neural tumors. The most common features of the disease include multiple neural tumors (neurofibromas) on the skin or within the body, pigmented skin lesions (ie., cafe au lait spots), and Lisch nodules (pigmented iris hamartomas).

Clinical diagnosis of NF1 requires 2 or more of the following:

- 6 or more café au lait spots $(>5 \mathrm{~mm}$ in diameter for prepubertal children and $>15 \mathrm{~mm}$ in post-pubertal patients)

- A plexiform neurofibroma (or 2 or more neurofibromas of any type)
- $\quad$ Crowe sign (multiple freckles in the axillary or inguinal region)

- A 1st degree relative with confirmed NF1

- Optic nerve "glioma"

- 2 or more Lisch nodules (hamartomas)

- $\quad$ Sphenoid dysplasia, cortical thinning in long bones, or other distinctive osseous lesion

\section{Case Report 1}

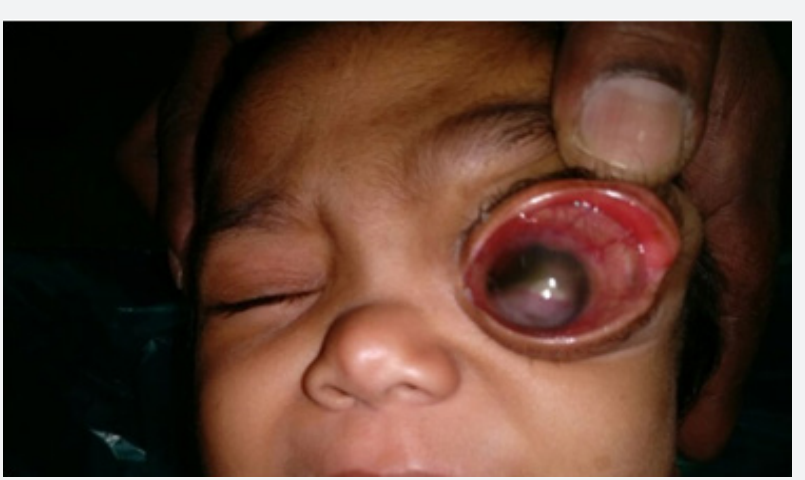

Figure 1: Proptosis of left eye with bupthalmos.

A 2 year old female child second by birth order, born out of non consanguineous marriage presented with history of forward displacement of left eye since birth, which gradual increase to present size. There were pigmented skin lesions all over body 
since birth (Figure 1). On examination, left eye proptosis with esotropia, normal head posture, inferior half of cornea showed opacity with vascularisation with circumcilliary congestion. Sclera thinning was noted on temporal aspect. Corneal diameter vertical $15 \mathrm{~mm}$ and horizontal $17 \mathrm{~mm}$ was noted with calliper suggestive of megalocornea. Ocular movement restricted. Iris pattern and fundus examination was not possible due to corneal opacity. Upper eyelid lateral aspect showed plexiform neurofibroma with hyper-pigmentation, on palpation was on right eye examination cornea was clear and of normal size, pupil reactive to light, iris showed altered pattern on examination under microscope but lisch nodules were absent (Figure 2). Indirect ophthalmoscope examination of fundus showed normal disc with normal blood vessel pattern [1]. The skin showed multiple cafe au lait spots (approximately 15 in total) with largest covering on right upper arm and axilla (Figure 3). Head circumference measured $47 \mathrm{~cm}$. Skull-dolicocephaly with open anterior and posterior frontanella. Systemic examination was within normal limit. Birth history-full term normal delivery, cried immediately after birth, no nicu admission, milestone development was normal and complete immunisation till date (Figure 4).

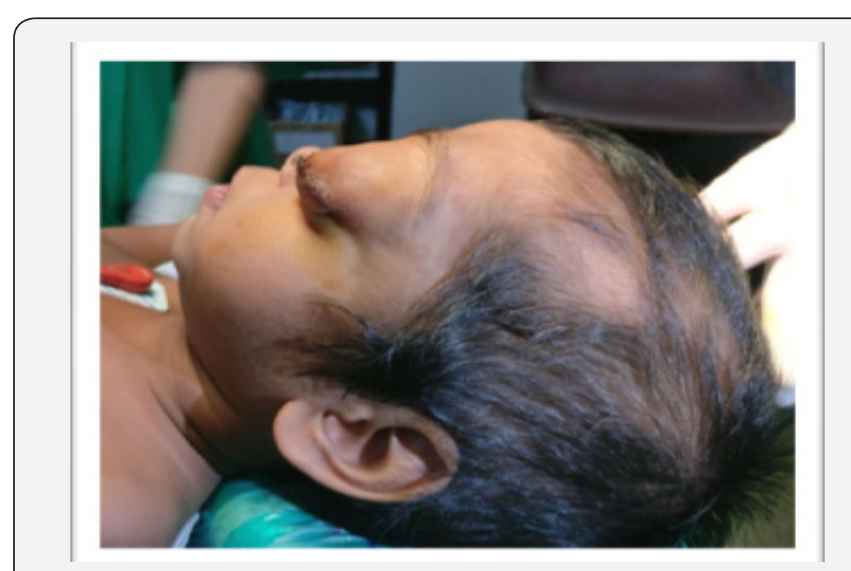

Figure 2: Plexiform neurofibroma on lateral aspect of upper eyelid.

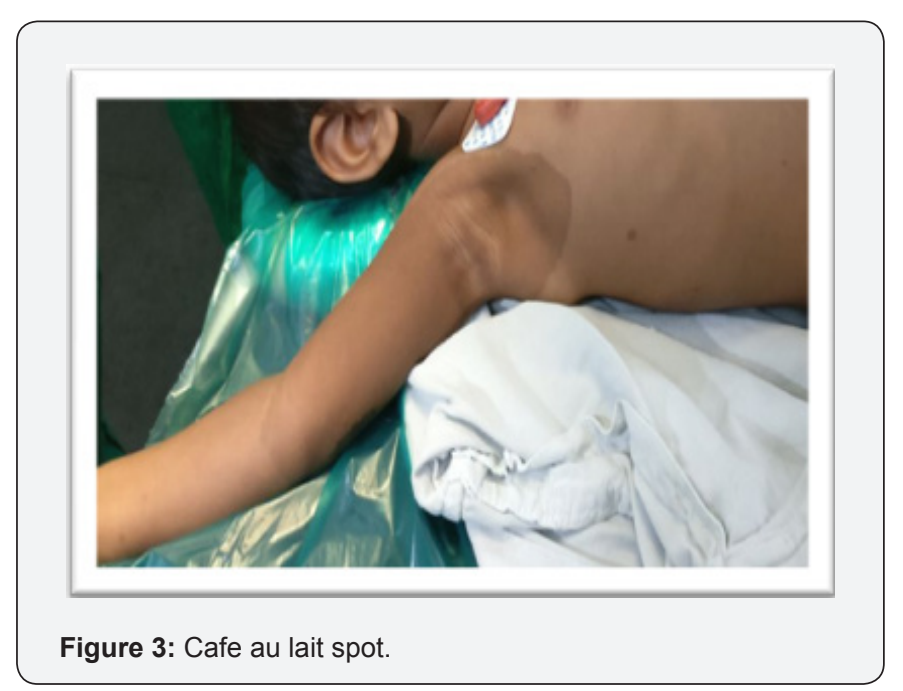

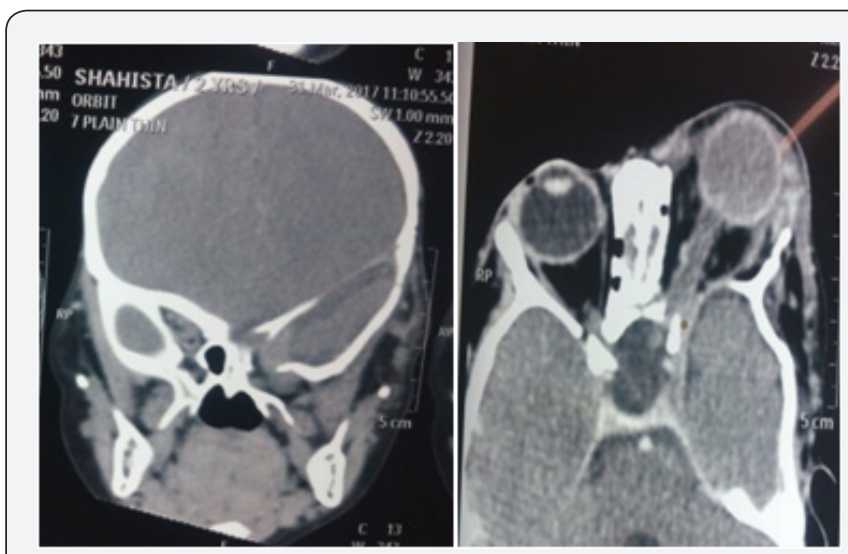

Figure 4: CT orbit showing left sphenoid wing dysplasia with proptosis of left eye.

Ct brain was suggestive of

- $\quad$ Left optic nerve sheath tumor

- $\quad$ Buphthalmos with proptosis on left side with disrupted globe architecture.

- Bulky extra-ocular muscle and lacrimal gland on left side.

- $\quad$ Left sphenoid wing dysplasia

- $\quad$ Linear thick enhancing soft tissue lesion involving medial part of middle cranial fossa with thickened dura peeping into the superior orbital fissure and orbital apex suggestive of Neurofibroma .

- $\quad$ Gliotic area in left occipital parafalcine region.

- $\quad$ Left hemimegalencephaly

- $\quad$ Thinning with sclerosis and irregularity involving left parietal bone.

- $\quad$ Right eyeball normal

- $\quad$ Right optic nerve and optic canal normal

Case 2

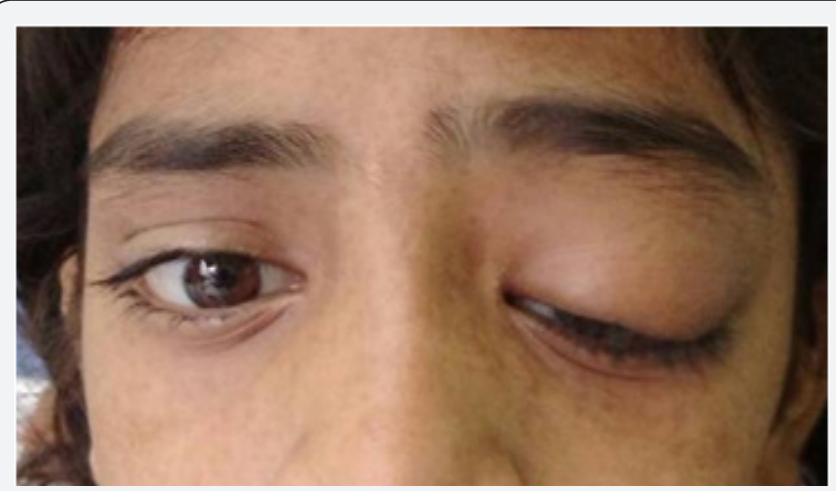

Figure 5: Left eye ptosis and plexiform neurofibroma. 


\section{type1 \\ Unilateral pulsatile eye with ptosis in neurofibromatosis}

A 12 year old girl presented with progressive diminution of vision in left eye since 1 month with painless and progressive drooping of left upper eyelid since childhood with no history of head/ocular trauma (Figure 5). Past medical, surgical and family history were not significant. Best corrected visual acuity were 6/6 in right and 6/36 in left eye. Left eye had mechanical ptosis obscuring the visual axis. Cutaneous plexiform neurofibroma noted in left upper eyelid. Left eyeball was pulsatile, synchronous with the carotid pulse, no thrill or bruits were detected over eyeball, forehead and neck. Ocular movements were full and free in all gazes. No apparent head posture noted. On slit lamp examination, multiple lisch nodules on iris of both eyes were detected. Intraocular pressure and dilated fundus examination were normal in both eyes. On general examination multiple café au lait spots present all over body. MRI orbit revealed, left sphenoorbital dysplasia with resultant meningiocele and cutaneous neurofibroma with left optic nerve unremarkable. Debulking of the upper lid neurofibroma was done with lid reconstruction to clear the visual axis. Meningocoele was left un-tackled. Post op patient is doing well [2].

\section{Case 3}

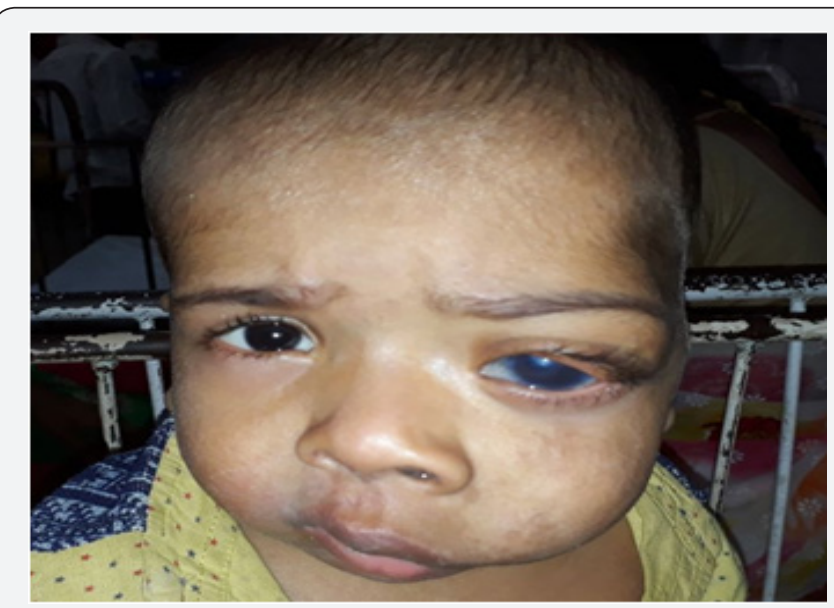

Figure 6: Left eye plexiform neurofibroma with Buphthalmos and left sided facial hemihypertrophy.

Unilateral plexiform neurofibroma with secondary congenital glaucoma associated with neurofibromatosis type1. 2 year old male boy came with complaint of protrusion of left eye associated with irritability when exposed to light and swelling of left side of face since birth (Figure 6). The child developed hyper-pigmented patches over his left side of face and whole body. His father also has same pigmented patches over his body. On examination under general anesthesia, left eye showed proptosis (measuring $21 \mathrm{~mm}$ on luedde's exophthalmometer) and plexiform neurofibroma involving upper eyelid (Figure 7 ). Left eye corneal diameter was $17 \mathrm{~mm}$ horizontally and $15 \mathrm{~mm}$ vertically with presence of haab's striae suggestive of buphthalmos. The average intraocular pressure (IOP) was
$10 \mathrm{mmHg}$ in the right eye and $17 \mathrm{mmHg}$ in left eye. Left eye had nasally subluxated lens. On gonioscopy examination both eyes showed open angles with the Schwalbe's line, Schlemm's canal and all of trabecula network seen. Fundus examination showed the maculas to be healthy however the cup/disc ratios were 0.3 in the right and 0.7 in the left and neural retina rims exhibited thinning and the ISNT sign was disrupted (Figure 8). MRI orbit reveals left bony orbit is larger in size with widening of superior orbital fissure and optical canal. Left globe is bulky in size with resultant mild proptosis and plexiform neurofibroma ,enlarged left intraocular muscle and optic nerve [3].

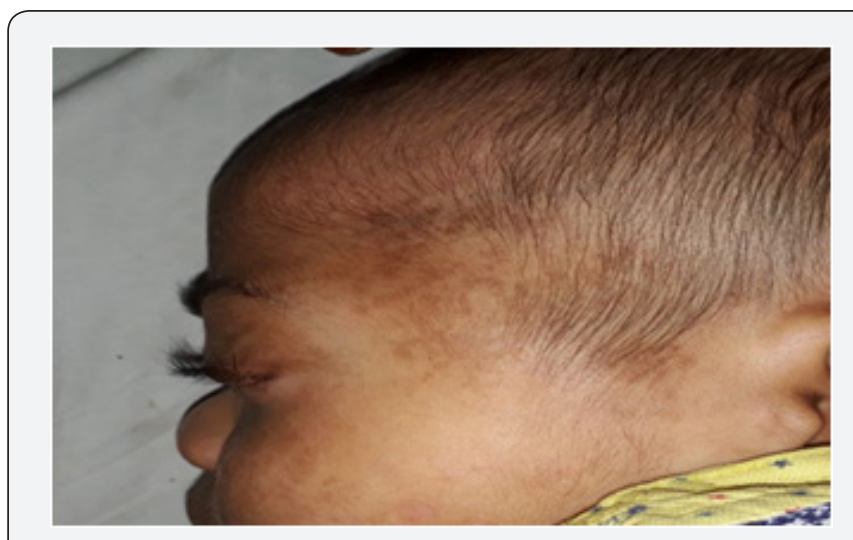

Figure 7: Café au lait spots.

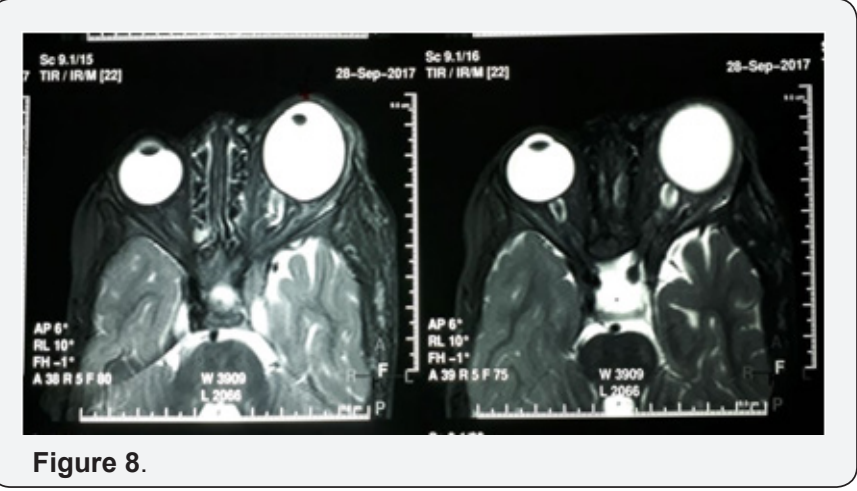

\section{Discussion}

Patient with neurofibromatosis (NF) manifest characteristic lesion composed of melanocytes or neuroglial cells,both of which are derivatives of neural crest mesenchyme. Almost all patients with NF1 have melanocytic lesions involving the skin and eye. Cafe-au-lait spots, the most common cutaneous expression, appear clinically as flat, sharply demarcated, uniformly hyperpigmented macules of varying size and shape. Clusters of small café-au-lait spots or freckling, in the axillary or inguinal regions are particularly characteristic of NF1.

Optic nerve glioma is a tumor of childhood, and presentation in adulthood may suggest malignant glioma. Diagnosis is usually made before 5 years of age, but occasionally the presentation is in early adulthood. There is no gender predilection. Optic nerve glioma accounts for $0.6 \%$ to $1.2 \%$ of all intracranial tumors. The 
incidence is 1 in 100,000 patients, with $90 \%$ presenting within the first two decades and $70 \%$ in the first decade. It represents about $17 \%$ of all the orbital tumors encountered in childhood. About half of the optic nerve gliomas are confined to the orbit, whereas half demonstrate intracranial extension. Intracranial extension may be suspected clinically on the basis of precocious puberty, somnolence, or diabetes insipid us. Any part of the optic pathway may be involved in a glioma, and prognosis depends in part upon the extent and location of the tumor. One or both optic nerves are involved in $24 \%$, the optic disc in $1.6 \%$ and the optic chiasma or tract in $75 \%$. In general, the more anterior the lesion, the better the prognosis Optic nerve glioma is a slowly growing pilocytic astrocytoma which typically affects children. Approximately $30 \%$ of patients have associated NF1. Malignant gliomas are rare and almost always occur in adults. Histology shows spindle-shaped pilocytic astrocytes and glial filaments.

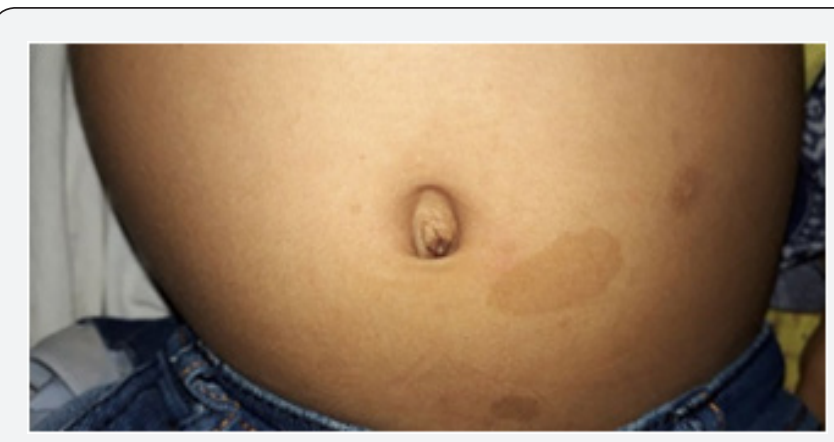

Figure 9.

Presentation is most frequently in the 1st decade (median age 6.5 years) with slowly progressive visual loss, followed later by proptosis, although this sequence may occasionally be reversed. Acute loss of vision as a result of haemorrhage into the tumour is uncommon. Proptosis often non-axial, with temporal or inferior dystopia. The optic nerve head, initially swollen subsequently becomes atrophic. Opticociliary collaterals and central retinal vein occlusion are occasionally seen. Intracranial spread to the chiasm and hypothalamus may develop. CT scan is diagnostic mostly presenting as fusiform enlargement of the optic nerve with a clear cut margin produced by the intact dural sheath. MR may be useful in showing intracranial extension.

Treatment may not be required in patients with no evidence of growth, good vision and no cosmetic deformity. Surgical excision with preservation of the globe is required in those with large or growing tumours that are confined to the orbit, particularly if vision is poor and proptosis significant. Radiotherapy may be combined with chemotherapy for tumours with intracranial extension that precludes surgical excision (Figure 9). Prognosis for life in childhood tumours is variable. Some have an indolent course with little growth, while others may extend intracranially and threaten life. Plexiform neurofibromas occur in 30\%of patients with NF1. It is soft subcutaneous swelling with indistinct margins. Approximately $10 \%$ of plexiform neurofibromas involve the face,commoly the upper eyelid(S-shaped deformity ).surgical de-bulking and frontalis suspension procedure can reduce ptosis sufficiently to permit binocular vision.

Secondary glaucoma can occur in neurofibromatosis due to obstruction of aqueous outflow in the angle, forward displacement of peripheral iris, thickening of ciliary body. Congenital glaucoma management associated with neurofibromatosis is very complex due to the frequent association of orbital and eyelid tumors and bone dysplasia, and its prognosis is usually poor. The good control of IOP has been achieved with medical and surgical (drainage device) management. The infantile form of glaucoma usually requires, and is responsive to, angle surgery (eg, goniotomy or trabeculotomy). For juvenile onset, where elevated episcleral venous pressure is the primary mechanism of the glaucoma, medical treatment generally works poorly, glaucoma drainage device can be tried. Trabeculectomy can also be considered, but it carries an increased device of expulsive and suprachoroidal hemorrhage. Differential diagnosis of optic nerve glioma should include idiopathic optic neuritis, sarcoidosis, demyelinating disease and optic nerve sheath meningioma. The treatment of optic nerve glioma is controversial. Observation is generally recommended if there is no clinical or radiographic evidence of progression of an optic nerve glioma. Surgical resection is successful in tumors confined to the optic nerve, with no useful vision or progression. The preferred technique is transcranial superior orbitotomy with preservation of the globe. Radiation therapy is generally reserved for patients over 5 years of age with progressive radiographic features or worsening clinical signs and symptoms. Chemotherapy is emerging as a possibly safer alternative to radiation therapy particularly in younger children. The prognosis of optic nerve glioma is quite variable and is in part based upon location. Most (80\%) have stable vision after an initial period of visual loss. The 10 year overall survival rate is between $85 \%$ to $100 \%$ in various series and spontaneous regression may occur.

\section{Conclusion}

Detailed examination and investigations are required before planning a de-bulking surgery in neurofibroma cases in order to provide a good cosmesis with a clear visual axis. Consistent follow up needed as patient may require further interventions.

\section{References}

1. Brad B, Salmon J (2015) Kanski's Clinical Ophthalmology, A systemic approach. ( $8^{\text {th }}$ edn), Élsevier, USA

2. Hsieh TD (2017) Neurofibromatosis Type 1.

3. Cassidy SB, Judith E (2010) Allanson Management of Genetic Syndromes. ( ${ }^{\text {rd }}$ edn), Wiley-Blackwell, New York, USA, 549-568. 
CC (1) This work is licensed under Creative

\section{Your next submission with Juniper Publishers} will reach you the below assets

- Quality Editorial service

- Swift Peer Review

- Reprints availability

- E-prints Service

- Manuscript Podcast for convenient understanding

- Global attainment for your research

- Manuscript accessibility in different formats

( Pdf, E-pub, Full Text, Audio)

- Unceasing customer service

Track the below URL for one-step submission https://juniperpublishers.com/online-submission.php 